\title{
Practical application of mathematical model techniques to predict effects of engineering works on tidal flow in estuaries with a large tidal range
}

N. V. M. ODD

\section{Dr R. Agnew, E. T. Smith, Sinclair, McNaught \& Partners, New Zealand}

In $\S 29$ the Author refers to departures from the steady flow velocity distribution but implies that there is little significant effect on the frictional resistance. I agree that this is generally true so far as magnitude of the frictional component is concerned, but there is a significant phase difference between it and the water surface slope, and there are small but measurable phase differences between velocities at different depths; the latter effect is evidenced by $\mathbf{S}$ shaped velocity distributions in homogeneous water quite distinct from distortion of the flow by fresh/salt water and wind effects. ${ }^{21}$

\section{Mr Odd}

It is reassuring to know that the magnitude of the frictional resistance term is not significantly affected by the unsteadiness of the flow in natural estuaries. As regards the phase difference between the resistance term $S_{\text {e }}$ and the water surface slope term $g(\partial h / \partial x)$ in equation (1); $S_{\mathrm{e}}$ is a function of the depth mean velocity, depth, roughness, sediment type and temperature. The momentum of the depth mean flow at slack water causes the resistance term to be out of phase with the water surface slope. A numerical model based on equations (1) and (2) will simulate this effect correctly.

58. As regards phase differences between velocities at different depths caused by inertia effects at slack water, Agnew ${ }^{22}$ has shown that the phase lag increases with the Lamb number $(L)$ for $L<15$.

$$
L=\frac{530}{T}\left(\frac{d}{a}\right)^{1 / 2}
$$

$T$ is the effective tidal period at slack water, $a$ is the acceleration of the depth mean velocity and $d$ is the depth of water.

59. The Lamb number in shallow estuaries with a large tidal range is usually of the order 5 or less, so that the velocity changes sign almost simultaneously at all depths in the absence of longitudinal density gradients.

60. The effect of longitudinal density gradients caused by the intrusion of saline water in either well-mixed (homogeneous in depth) or stratified estuaries has a much larger effect on the velocity profile. ${ }^{22.23}$ The internal longitudinal circulation in an estuary can be simulated in either a fully two-dimensional $x-z$ model or in simpler two-layer models such as those described by Odd and Owen. ${ }^{24}$

\section{References}

21. Agnew R. A two layer theory for unsteady flow. Proc. 2nd Aust. Conf. Hydraul. Fluid Mech., 1966, A97.

22. AGNEw R. Tidal streams in natural and artificial channels. PhD thesis, Queen's University, Belfast, 1959.

23. MCGREGor R. C. The influence of topography and pressure gradients on shoaling in an estuary. Geophys. Inl Roy. Astr. Soc., 1971, 25, 469-480.

24. ODD N. V. M. and OWEN M. W. A two-layer model of mud transport in the Thames Estuary. Proc. Instn Civ. Engrs, 1972, Suppl. (ix) 175-205.

Paper published: Proc. Instn Civ. Engrs, 1971, 50, Dec., 507-519. 